Molecules 1999, 4, M94

\title{
A New Diglycoside of Diterpene from Ageratina vacciniaefolia
}

\section{Rubén Torrenegra*, Jorge Robles, Julio Pedrozo and Beatriz Pescador}

Pontificia Universidad Javeriana, Grupo de Investigación Fitoquímica GIFUJ, Santafé de Bogotá, Colombia

Phone: 3208320, fax 2850503, E-mail rtorrene@javercol.javeriana.edu.co

Received: 19 March 1999 / Published: 16 April 1999

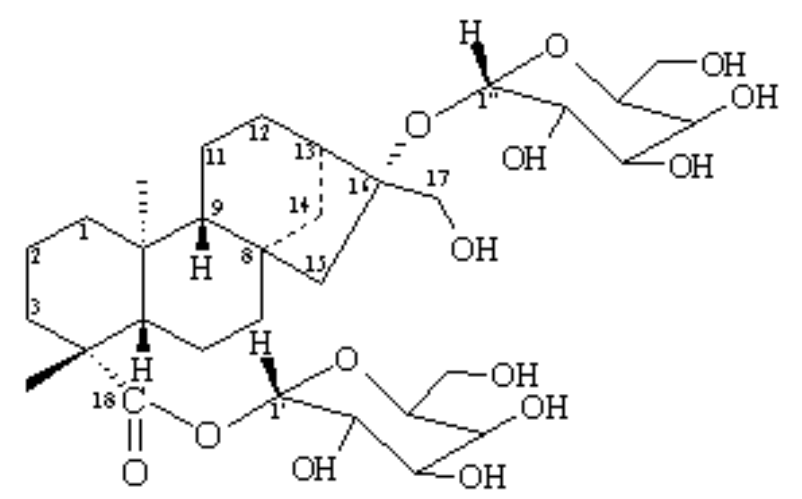

From leaves and flowers of Ageratina vacciniaefolia [1-7] we have isolated several compounds: a flavonoid, a diterpene [8] and a new compound identified as b-D-glucopyranosil ester of (-)17-(bglucopiranosyloxyl)-16-hydroxy-kauran-19-oic acid (see the formula). The structure was established by using ${ }^{1} \mathrm{HNMR},{ }^{13} \mathrm{CNMR}, \mathrm{COSY}$, NOESY and HMBC spectroscopic techniques (Table 1) [1,7].

Table 1. The assignment of the NMR data [2-6].

\begin{tabular}{|c|c|c|}
\hline No. C & Type of C & d -ppm \\
\hline 19 & $-\mathrm{COO}$ & 178.2 \\
\hline $1^{*}$ & $\mathrm{CH}$ (anomeric) & 98.5 \\
\hline $1 * *$ & $\mathrm{CH}$ (anomeric) & 95.6 \\
\hline \multirow[t]{9}{*}{16} & $\mathrm{C}-\mathrm{O}$ & 91.4 \\
\hline & $\mathrm{CH}-\mathrm{O}$ & 78.7 \\
\hline & $\mathrm{CH}-\mathrm{O}$ & 78.7 \\
\hline & $\mathrm{CH}-\mathrm{O}$ & 78.3 \\
\hline & $\mathrm{CH}-\mathrm{O}$ & 77.7 \\
\hline & $\mathrm{CH}-\mathrm{O}$ & 75.2 \\
\hline & $\mathrm{CH}-\mathrm{O}$ & 74.1 \\
\hline & $\mathrm{CH}-\mathrm{O}$ & 71.4 \\
\hline & $\mathrm{CH}-\mathrm{O}$ & 71.1 \\
\hline \multirow[t]{3}{*}{17} & $\mathrm{CH}_{2}-\mathrm{O}$ & 63.6 \\
\hline & $\mathrm{CH} 2 \mathrm{OH}$ & 62.5 \\
\hline & $\mathrm{CH} 2-\mathrm{O}$ & 62.4 \\
\hline
\end{tabular}




\begin{tabular}{|c|c|c|}
\hline 9 & $\mathrm{CH}$ & 58.5 \\
\hline 5 & $\mathrm{CH}$ & 57.3 \\
\hline 15 & $\mathrm{CH}_{2}$ & 51.4 \\
\hline solv. & solv. & 49.8 \\
\hline 8 & $\mathrm{C}$ & 46.0 \\
\hline 4 & C & 45.1 \\
\hline 13 & $\mathrm{CH}$ & 44.2 \\
\hline 7 & $\mathrm{CH}_{2}$ & 43.1 \\
\hline 1 & $\mathrm{CH}_{2}$ & 41.8 \\
\hline 10 & C & 40.9 \\
\hline 3 & $\mathrm{CH}_{2}$ & 39.1 \\
\hline 14 & $\mathrm{CH}_{2}$ & 37.6 \\
\hline 18 & $\mathrm{CH}_{3}$ & 29.1 \\
\hline 12 & $\mathrm{CH}_{2}$ & 26.8 \\
\hline 6 & $\mathrm{CH}_{2}$ & 23.2 \\
\hline 11 & $\mathrm{CH}_{2}$ & 20.1 \\
\hline 2 & $\mathrm{CH}_{2}$ & 19.7 \\
\hline 20 & $\mathrm{CH}_{3}$ & 16.4 \\
\hline
\end{tabular}

The ${ }^{13}$ CNMR spectrum showed totally 32 signals, 12 of them at ca. 62-99 ppm which are characteristic of glycoside. The rest 20 signals are attributed to the aglicone which is a compound of diterpene kaurane type, and the structure has been confirmed by both ${ }^{13} \mathrm{CNMR}$ and ${ }^{1} \mathrm{HNMR}$ spectra.

The signals from ${ }^{1} \mathrm{HNMR}$ at $\mathrm{d} 4.48 \mathrm{ppm}(\mathrm{d}, J=7.2 \mathrm{~Hz})$ was assigned to the anomeric proton, whcih has a direct correlation with $\mathrm{C}$ of d $98.45 \mathrm{ppm}$ indicating a b-glycoside; while ${ }^{1} \mathrm{HNMR}$ signals appear at d 5.434 ppm $(\mathrm{d}, J=7.2 \mathrm{~Hz})$ coupling directly with $\mathrm{C}$ at $\mathrm{d} 95.56 \mathrm{ppm}$ can be attributed to a b-glucose ester.

Furthermore, the absence of signals to vinilic protons and the absence of signals to $\mathrm{C} 9$ and $\mathrm{C} 15$ connected to oxygen, similar to those in the other compound [8], indicate that this aglicone compound is a Kaurane derivative. The signal from ${ }^{13} \mathrm{CNMR}$ spectrum at $\mathrm{d} 63.60 \mathrm{ppm}$ showed a $-\mathrm{CH}_{2} \mathrm{OH}$ connected to $\mathrm{C} 17$ which was confirmed by correlation observed on HMBC and NOESY spectra. A signal at $\mathrm{d} 91.55 \mathrm{ppm}$ indicating a glucose connected to $\mathrm{C} 16$ is confirmed by a long range correlation on HMBC spectrum. An enzymatic hydrolysis of this compound with b-glucosidase also confirmed the structure purposed.

In summary, this compound was identified as b-D-glucopyranosil ester of (-)17-(bglucopiranosyloxyl)-16-hydroxykauran-19-oic acid by using HNMR and ${ }^{13}$ CNMR spectra analysis and enzymatic hydrolysis with b-glucosidase [7].

The ethanolic extract from leaves and flowers of $A$. vacciniaefolia yielded white crystals after column chromatography and eluted with $\mathrm{CH}_{2} \mathrm{Cl}_{2}$, EtOAc and mixtures of these solvents. The compound was purified further by column chromatography on RP-18 eluted with $\mathrm{MeOH}-\mathrm{H}_{2} \mathrm{O}$ (2:1).

M.p. $198^{\circ} \mathrm{C}$.

$[\mathrm{a}]^{20} \mathrm{D}=-52.5(0.0043 \mathrm{MeOH})$. 
DCIMS [isobutane] m/z: 499; 481; 463; 419; 392; 391; 361; 319; 273; 163; 145 (100\%); 127.

${ }^{1} \mathrm{HNMR}\left(360 \mathrm{MHz}, \mathrm{CD}_{3} \mathrm{OD}\right)$ : d in ppm, $0.96\left(\mathrm{~s}, 3 \mathrm{H}, \mathrm{CH}_{3}\right) ; 1.20\left(\mathrm{~s}, 3 \mathrm{H}, \mathrm{CH}_{3}\right) ; 1.45(\mathrm{~m}, 1 \mathrm{H}) ; 1.85(\mathrm{~m}, 1 \mathrm{H})$; 2.25 (m, 1H); 3.18 (m, 1H); $3.33(\mathrm{~m}, 1 \mathrm{H}) ; 3.37$ (m, 2H); 3.7 (dd, 1H, $J=12.3 \mathrm{~Hz}) ; 3.8$ (dd, $1 \mathrm{H}, J=12.2 \mathrm{~Hz}$ ); 4.48 (d, $1 \mathrm{H}, J=7.2 \mathrm{~Hz}$, anomeric proton); 5.43 (d, $1 \mathrm{H} J=7.2$, anomeric proton).

${ }^{13} \mathrm{CNMR}\left(90.5 \mathrm{MHz}, \mathrm{CD}_{3} \mathrm{OD}\right): \mathrm{d} 16.38\left(-\mathrm{CH}_{3}, \mathrm{C}\right) ; 19.71 ; 29.05\left(-\mathrm{CH}_{3}, \mathrm{C}\right) ; 20.12 ; 25.17 ; 26.82 ; 37.62$; $39.05 ; 40.92 ; 41.84 ; 43.07 ; 44.21 ; 45.08 ; 45.97 ; 51.40 ; 57.29 ; 58.54 ; 62.40 ; 62.52\left(-\mathrm{CH}_{2} \mathrm{OH}\right) ; 63.60$ (-CH $2-\mathrm{O}-) ; 71.10 ; 71.42 ; 74.08 ; 75.18 ; 77.73 ; 78.29 ; 78.64$ (2C); 91.55; 95.56; 98.45; 178.16 (-COO, C19). For details, see the following table (Table 1).

Acknowledgments: Project code 1203-05-394-95, CT-128-97, supported by COLCIENCIAS.

\section{References}

1. Hasan, C. M., Healey, T. M. and Waterman P. T. Phytochemistry 1982, 21, 1365.

2. Demetzos, C., Harvala, C., Phillianos, S. Manol Skaltsounis, A. J. Nat. Prod. 1991, 53, 1365.

3. Torrenegra, R., Pedrozo, J., Robles, J., Waibel, R. and Achenbach, H. Phytochemistry 1992, 31, 2415.

4. Konzi, S. A. and McChesney, J. D. J. Nat. Prod. 1991, 54, 483.

5. Aranda, G., El Kortbi, M. S., Lallemand, J. Y. Tetrahedron 1991, 47, 8339.

6. Konig, W. A., Lutz, S. and Wenz, G. Angew. Chem. 1988, 100, 989.

7. Breitmaier Eberhard, Structure Elucidation by NMR in Organic Chemistry, John Wiley \& Sons, New York (1993).

8. Torrenegra, R., Robles, J., Pedrozo, J., Pescador B. Molecules 1999, 4, M92.

Sample Availability: Available from the authors and from MDPI. MDPI 16329.

(C)1999 MDPI. All rights reserved. Molecules website http://www.mdpi.org/molecules/ 